\title{
Numerical modelling of calcination reaction mechanism for cement production
}

\author{
Hrvoje Mikulčićc ${ }^{a, *}$, Eberhard von Berg ${ }^{b}$, Milan Vujanović ${ }^{a}$, Peter Priesching ${ }^{b}$, Luka Perković ${ }^{a}$, \\ Reinhard Tatschl ${ }^{\mathrm{b}}$, Neven Duić ${ }^{\mathrm{a}}$ \\ ${ }^{a}$ Faculty of Mechanical Engineering and Naval Architecture, University of Zagreb, Ivana Lučića 5, 10000 Zagreb, Croatia \\ ${ }^{\mathrm{b}}$ AVL-AST, Hans List Platz 1, Graz, Austria
}

\section{A R T I C L E I N F O}

\section{Article history:}

Received 25 July 2011

Received in revised form

11 November 2011

Accepted 15 November 2011

Available online 23 November 2011

\section{Keywords:}

Calcination

Mathematical modelling

Reaction engineering

Multiphase reactions

Porous media

Particle

\begin{abstract}
A B S T R A C T
Calcination is a thermo-chemical process, widely used in the cement industry, where limestone is converted by thermal decomposition into lime $\mathrm{CaO}$ and carbon dioxide $\mathrm{CO}_{2}$. The focus of this paper is on the implementation and validation of the endothermic calcination reaction mechanism of limestone in a commercial finite volume based CFD code. This code is used to simulate the turbulent flow field, the temperature field, concentrations of the reactants and products, as well as the interaction of particles with the gas phase, by solving the mathematical equations, which govern these processes. For calcination, the effects of temperature, decomposition pressure, diffusion and pore efficiency were taken into account. A simple three-dimensional geometry of a pipe reactor was used for numerical simulations. To verify the accuracy of the modelling approach, the numerical predictions were compared with experimental data, yielding satisfying results and proper trends of physical parameters influencing the process.
\end{abstract}

(c) 2011 Elsevier Ltd. All rights reserved.

\section{Introduction}

During the cement manufacturing process, large amounts of carbon dioxide are emitted. There are two processes from which carbon dioxide is produced. One of the processes is the combustion of the fossil fuel and the other is the calcination reaction. Because of the effect of global warming and particularly because carbon dioxide is one of the primary greenhouse gases, in-depth understanding of these processes is relevant for the development of effective cement production and reduction of carbon dioxide emission.

Calcination is a strongly endothermic process where limestone (calcium carbonate) $\mathrm{CaCO}_{3}$ is converted by thermal decomposition into lime (calcium oxide) $\mathrm{CaO}$ and carbon dioxide $\mathrm{CO}_{2}$. The process of calcination (thermal decomposition of a limestone particle) in a cement calciner can be divided into three stages (Bes, 2006): (a) heat energy transported by calciner gases (i.e. combustion products and exhaust gases from the rotary kiln) supplied to the limestone particle by convection and radiation, pre-heats the particle from the ambient temperature to the

\footnotetext{
*Corresponding author. Tel.: +38516168 494; fax: +38516156940.

E-mail addresses: hrvoje.mikulcic@fsb.hr (H. Mikulčić),

eberhard.von.berg@avl.com (E. von Berg), milan.vujanovic@fsb.hr (M. Vujanović), peter.priesching@avl.com (P. Priesching), luka.perkovic@fsb.hr (L. Perković), reinhard.tatschl@avl.com (R. Tatschl), neven.duic@fsb.hr (N. Duić).
}

decomposition temperature. The decomposition temperature reported in the literature (Stanmore and Gilot, 2005) is in the temperature range from $600{ }^{\circ} \mathrm{C}$ to $900{ }^{\circ} \mathrm{C}$, depending on the type of limestone; (b) at the decomposition temperature, when the pressure of carbon dioxide produced by the decomposition of limestone at the particle surface is greater than the partial pressure of carbon dioxide in the surrounding gas, the process of calcination begins, making a lime shell around the limestone core; (c) by conduction the heat passes through the porous layer increasing the internal temperature, which causes continued calcination. The released carbon dioxide diffuses through the porous layer to the surface and by convection is released into the calciner. As long as the particle temperature increases and the partial pressure of $\mathrm{CO}_{2}$ is below the decomposition pressure, the process of calcination will continue until all the limestone is converted into lime.

The calcination process that takes place in a calciner for cement production is of particular importance because it affects energy consumption and pollutant emissions. A calciner is a separate furnace used prior to the rotary cement kiln, where the limestone, pulverised coal and rotary kiln exhaust gases are mixed. Thus, an in-depth understanding of the physical and chemical processes in the calciner is relevant for the development of effective cement production.

Recently, because of the increased reductions in carbon dioxide emissions as well as reductions of other pollutant emissions 
(Vujanović et al., 2007), different types of calciners with different operating conditions have been studied. Fidaros et al. (2007) presented a numerical model and a parametric study of the gaseous flow and the transport phenomena that take place in a vertical industrial low $\mathrm{NO}_{x}$ calciner, showing good prediction capabilities of velocity, temperature and distribution of particles. Iliuta et al. (2002b) developed a mathematical model for an in-line low- $\mathrm{NO}_{x}$ calciner based on reaction-diffusion approach for calcination and combustion. Also Iliuta et al. (2002a) reported the effect of different operating conditions in an in-line low- $\mathrm{NO}_{x}$ calciner in their parametric study, showing that the influence of different operating conditions has an impact on the level of calcination, burn-out and NO emission. Hu et al. (2006) used a three-dimensional Eulerian-Lagrangean model to simulate a dual combustor and precalciner to predict the burn-out rate of coal and the decomposition rate of limestone. Huang et al. (2006) carried out a three-dimensional simulation of an in-line swirl-spray precalciner with a new method for particle-wall boundary condition and with a four-mixture-fraction model to describe the multi-component mutual transportation in a precalciner. Huanpeng et al. (2004) used a two-dimensional model to study the impact of various parameters on the dynamics of the two-phase flow in a precalciner, representing the transport properties of the solid phase with the kinetic theory of granular flow. All of these studies show that there is a great potential in research and the development of calciners, especially regarding the thermo-chemical reactions that take place in the calciner, e.g. calcination, combustion and pollutant formation. Although there have been numerous studies about the calcination reaction mechanism, the basis of current calcination mathematical models was completed during the mid-1980's. Borgwart (1985) investigated the calcination kinetics and demonstrated that heat and mass transfer in a particle determines the reaction rate. He also reported that the maximum calcination reaction rate is achieved when the limestone particle size is minimised, because the mass transport of $\mathrm{CO}_{2}$ through the product layer has a lesser influence on the rate of decomposition. His results provided useful data for the rates of limestone decomposition. Dennis and Hayhurst (1987) ran a series of experiments in a fluidized bed, and by changing the gas pressure and temperature found the influence of $\mathrm{CO}_{2}$ partial pressure on the rate of calcination. Campbell et al. (1970) and Hills (1968) found that the decomposition of limestone is controlled by the mass transfer through the product layer and by the heat transfer. Ingraham and Marier (1963) found that the decomposition rate depends linearly on the difference between the equilibrium pressure of the calcination process and the $\mathrm{CO}_{2}$ pressure at the reaction surface. Darroudi and Searcy (1981) found that at $\mathrm{CO}_{2}$ partial pressures below 0.01 bar the rate is practically independent, whereas at higher pressure values a linear dependency was found. Silcox et al. (1989) used the experimental data produced by Borgwardt to develop a mathematical model of the calcination of limestone. $\mathrm{Hu}$ and Scaroni (1996) investigated the influence of particle size on the rate of calcination and found that for particles bigger than $20 \mu \mathrm{m}$ and gas flow temperatures above $1473 \mathrm{~K}$ heat transfer and pore diffusion are the rate-controlling factors. For particles smaller than $10 \mu \mathrm{m}$ and gas flow temperatures below than $1073 \mathrm{~K}$ they found that chemical kinetics are the rate-controlling factors. Most of the authors (Garcia-Labiano et al., 2002; Hu and Scaroni, 1996; Khinast et al., 1996) consider the mass transfer of $\mathrm{CO}_{2}$ from the reaction interface through the porous lime layer to the surface of the particle and the chemical reaction as the rate-controlling factors. Garcia-Labiano et al. (2002), along with their experiment, demonstrated different behaviours of different types of limestone during the calcination process. As a result of this finding they stated that the appropriate mathematical model for calcination, the shrinking core or the changing grain size model, must be used to appropriately define the reaction rate parameters of the particular type of limestone. A study by Mohr (2001) describes in detail the mathematical model of the calcination process, showing the impact of various parameters on the rate of calcination. Following Mohr's study, Hillers (2008) investigated the influence of numerical turbulence models on the calcination results using the same calcination model.

The purpose of this paper is to present a numerical model of the calcination process implemented into a commercial CFD code that is detailed enough to contain the relevant physical and chemical processes e.g., Arrhenius rate approach, pressure limitation, diffusion resistance, porosity, tortuosity, pore size and pore efficiency. The latter features are treated with parameters understood as averages over the grain topology and size. Thus this procedure avoids uncertain additional assumptions needed for more detailed sub-models, but is still sufficiently accurate and simple enough to run on meshes of appropriate size and resolution as it is needed for detailed CFD simulations of realistic industrial calcination devices. This balance is regarded as characteristic feature of the approach presented. To verify the accuracy of the modelling approach, the numerical predictions were compared with the experimental data that are given in the literature (Mohr, 2001).

\section{Numerical model}

\subsection{Continuous phase}

The fundamental equations of continuum mechanics are based on the conservation laws for mass, momentum and energy. The general form of the time averaged conservation equation for any dependent variable $\varphi$ of the continuous phase in the differential form is

$\frac{\partial}{\partial t}(\rho \varphi)+\frac{\partial}{\partial x_{j}}\left(\rho \varphi u_{j}\right)=\frac{\partial}{\partial x_{j}}\left(\Gamma_{\varphi} \frac{\partial \varphi}{\partial x_{j}}\right)+S_{\varphi}$,

where $\rho$ is the density, $u_{j}$ Cartesian velocity, $\Gamma_{\varphi}$ diffusion coefficient and $S_{\varphi}$ is the source term of the dependent variable $\varphi$.

\subsection{Calcination reaction mechanism}

In the CFD-code used in this study, the motion and transport of the solid particles are tracked through the flow field using the Lagrangian formulation, while the gas phase is described by solving conservation equations using the Eulerian formulation. Solid particles are discretized into finite numbers of particle groups, known as parcels, which are assumed to have same size and also the same physical properties. The parcels are tracked as they move through the calculated flow field using a set of equations that describe their dynamics. The coupling between the parcels and the gaseous phase is taken into account by introducing appropriate source terms for mass, momentum and enthalpy exchange (Vujanović, 2010).

The mathematical model used for the calcination calculation is treated in the Lagrangian spray module, where thermo-chemical reactions occur inside a particle as well as between particle components and gas phase species. The described calcination model was integrated into the commercial CFD code FIRE, using FIRE's user-defined functions capability. User functions, written in FORTRAN programming language, were linked with the AVL's FIRE code (Baburić et al., 2004, 2005; Vujanović et al., 2009), providing prediction of calcination process on one hand and retaining all the usual FIRE features on the other. In general the 
calcination process can be presented by the following equation:

$\mathrm{CaCO}_{3}(\mathrm{~s}) \rightarrow \mathrm{CaO}(\mathrm{s})+\mathrm{CO}_{2}(\mathrm{~g})+178 \mathrm{~kJ} / \mathrm{mol}$.

In this study the mathematical model of the calcination process, based on the chemical reaction scheme published by Silcox et al. (1989), is extended with the effects of diffusion limitation of the overall rate and the pore diffusion effectiveness factor. The calcination model involves three rate-limiting processes: (a) heat transfer to the particle, (b) mass transfer of $\mathrm{CO}_{2}$ from the reaction interface through the porous layer and particle boundary layer to the surrounding and (c) the kinetics of the chemical reaction.

The calcination process starts only if the partial pressure of carbon dioxide in the gas surrounding the limestone surface is less than the decomposition pressure of limestone (Stanmore and Gilot, 2005). The decomposition pressure $P_{e q}$ and the chemical reaction rate $k_{c h}$ of the calcination process determined by Silcox et al. (1989) are

$p_{e q}=4.137 \times 10^{12} \exp \left(-\frac{20474}{T}\right)[\mathrm{Pa}]$,

$k_{c h}=k_{D}\left(p_{e q}-p_{\mathrm{CO}_{2}}\right)\left[\mathrm{molm}^{-2} \mathrm{~s}^{-1}\right]$,

where $p_{\mathrm{CO}_{2}}$ is the partial pressure of carbon dioxide at the reaction surface of limestone and

$k_{D}=1.22 \exp \left(-\frac{4026}{T}\right) \times 10^{-5}\left[\mathrm{~mol} \mathrm{~m}^{-2} \mathrm{~s}^{-1} \mathrm{~Pa}^{-1}\right]$.

Based on the Eqs. (2) and (4), Eq. (3) for the chemical reaction rate of the calcination process can be written in the following form:

$$
\begin{aligned}
k_{c h}= & 5.0 \times 10^{7} \exp \left(-\frac{24500}{T}\right)-1.22 \\
& \times 10^{-5} \exp \left(-\frac{4026}{T}\right) p_{\mathrm{CO}_{2}} \frac{A_{\text {por }}}{A_{\text {geom }}}\left[\mathrm{mol} \mathrm{m}^{-2} \mathrm{~s}^{-1}\right] .
\end{aligned}
$$

Major effects such as temperature, $\mathrm{CO}_{2}$ partial pressure and enhanced overall surface due to porosity are taken into account in this equation. The surface increase is modelled as $A_{\text {por }} / A_{\text {geom }}$, where $A_{p o r}$ is the overall reaction surface (representing the surface of internal pores and the outer surface of the sphere), and $A_{\text {geom }}$ is the surface of the particle (sphere). The surface increase is dependent on porosity, pore diameter and topology of the porous structure, which are not known in detail for the limestone considered in the experiments discussed below. Thus in this work it is used as a matching parameter for the specific type of limestone with typical values ranging from 1 to 5 . This parameter has some initial value depending on type of limestone, but starting with this value it will also evolve during the reaction by shrinking and cracking processes as well as by sintering. Since the latter processes partly increase and partly decrease the surface the assumption of a mean average or balanced value is supported.

As illustrated in Fig. 1 partial pressure of $\mathrm{CO}_{2}$ greatly influences the reaction rate. At higher temperatures and lower $\mathrm{CO}_{2}$ partial pressure the rate of change of the reaction rate is much faster than for lower temperature and higher $\mathrm{CO}_{2}$ partial pressure values. For the above diagram the effect of porosity was not taken into account, i.e., the value of $A_{\text {por }} / A_{\text {geom }}$ was set to 1 .

The physical reaction rate $k_{p h}$ of the calcination process is determined from

$k_{p h}=\frac{12 D S h}{R_{\mathrm{CO}_{2}} d_{\text {part }} T} p_{\text {ref }}\left[\mathrm{kg} \mathrm{m}^{-2} \mathrm{~s}^{-1}\right]$

which represents the mechanism of diffusion limitation (Schneider, 2003). Due to high $\mathrm{CO}_{2}$ concentration in the pore system and in the

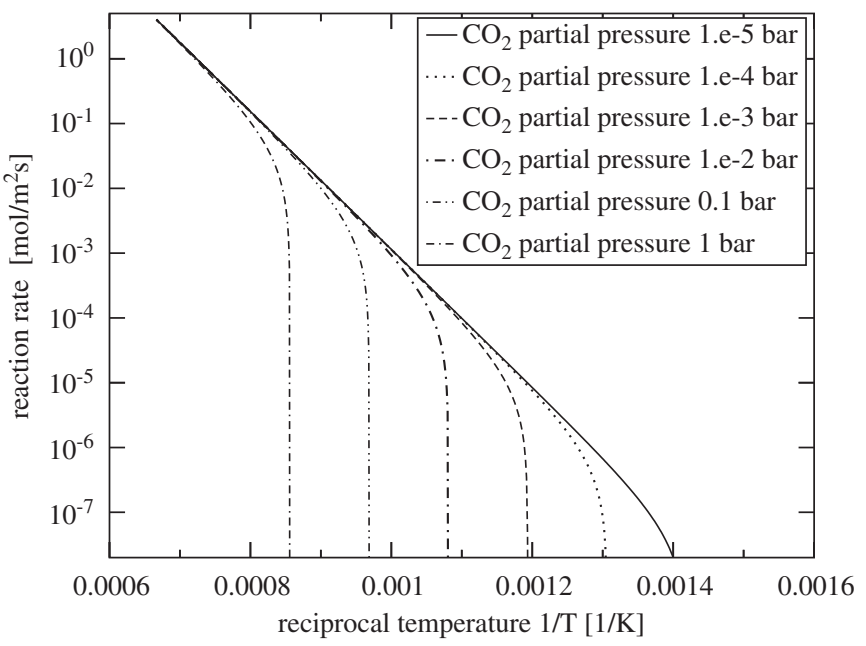

Fig. 1. Effect of $\mathrm{CO}_{2}$ partial pressure on the chemical reaction rate.

particle surrounding the partial pressure of $\mathrm{CO}_{2}$ is assumed to be high as well and the reference pressure $p_{\text {ref }}$ in Eq. (6) is assumed to be close to ambient pressure. Following Schneider (2003) the Sherwood number is taken as 2 , since limestone particles are small and rapid velocity equilibration can be assumed. The term $D$ represents the diffusion coefficient that consists of binary and Knudsen diffusion coefficient (Kern and Jess, 2006) and is calculated as

$D=\left[\frac{1}{D_{b i n}}+\frac{1}{D_{k n u}}\right]^{-1}\left[\mathrm{~m}^{2} \mathrm{~s}^{-1}\right]$.

For the binary diffusion coefficient the following correlation demonstrated by Reid et al. (1988) is used:

$D_{\text {bin }}=\frac{0.0266 T^{1.5}}{p M_{A B}^{0.5} \sigma_{A B}^{2} \omega_{d}}\left[\mathrm{~m}^{2} \mathrm{~s}^{-1}\right]$,

while the Knudsen diffusion coefficient (Bluhm-Drenhaus et al., 2010) is calculated as

$D_{k n u}=\frac{d_{\text {pore }}}{3}\left[\frac{8 R_{\mathrm{CO}_{2}} T}{\pi}\right]^{0.5}\left[\mathrm{~m}^{2} \mathrm{~s}^{-1}\right]$.

The overall reaction rate of the calcination process, which is the component of the physical and the chemical reaction rate, based on Levenspiel (1972) is calculated as

$k=\left[\frac{1}{k_{p h}}+\frac{1}{\eta \tilde{k}_{c h}}\right]^{-1}\left[\mathrm{~kg} \mathrm{~m}^{-2} \mathrm{~s}^{-1}\right]$,

where $\tilde{k}_{c h}$ is the chemical reaction rate in $\left[\mathrm{kg} \mathrm{m}^{-2} \mathrm{~s}^{-1}\right]$ and $\eta$ is the effect of pore efficiency on the chemical reaction rate of calcination process. Here the pore efficiency coefficient $\eta$ is applied globally to the chemical reaction rate assumed to take place inside the complex topology of the porous structure. The coefficient $\eta$ is given by Froment and Bischoff (1990) as

$\eta=\frac{\tanh \left[\frac{d}{6} \sqrt{\frac{\overline{\bar{k}}_{c h}}{\varepsilon D}}\right]}{\left[\frac{d}{6} \sqrt{\frac{\overline{\bar{k}}_{c h}}{\varepsilon D}}\right]}$,

where $\overline{\bar{k}}_{c h}$ is the chemical reaction rate in $\left[\mathrm{s}^{-1}\right]$ and the correction factor $\varepsilon$ given by Bluhm-Drenhaus et al. (2010) applied to the diffusion coefficient $D$ is

$\varepsilon=\frac{\varepsilon_{p}}{\tau_{p}^{2}}$, 
where $\varepsilon_{p}$ denotes the void fraction of the limestone particle with higher values favouring diffusion, $\tau_{p}$ denotes the tortuosity, which can be regarded as a measure for the complexity of the pore structure hindering the diffusion of the reacting gases inside the porous structure of the grains.

Fig. 2 illustrates the impact of the chemical reaction rate and the physical limitation on the overall reaction rate of the calcination process. It is clear that at higher temperatures, physical limitation has a significant influence on the overall calcination rate. Since the experimental conditions of Mohr's experiment are covering the transition region shown in Fig. 2, the diffusion limitations must be taken into account in the simulations.

Mass exchange from the calcination reaction is calculated for the limestone, lime and carbon dioxide. The mass transfer rate of limestone is calculated by the following equation:

$\dot{m}_{\mathrm{CaCO}_{3}}=-\widehat{k}\left[\mathrm{~kg} \mathrm{~s}^{-1}\right]$,

where $\widehat{k}$ is the overall reaction rate of the calcination process in $\left[\mathrm{kg} \mathrm{s}^{-1}\right]$ and from stoichiometry the mass transfer of lime and carbon dioxide are

$\dot{m}_{\mathrm{CaO}}=\overparen{k} \frac{M_{\mathrm{CaO}}}{M_{\mathrm{CaCO}_{3}}}\left[\mathrm{~kg} \mathrm{~s}^{-1}\right]$,

$\dot{m}_{\mathrm{CO}_{2}}=\widehat{k} \frac{M_{\mathrm{CO}_{2}}}{M_{\mathrm{CaCO}_{3}}}\left[\mathrm{~kg} \mathrm{~s}^{-1}\right]$.

Enthalpy exchange from the calcination reaction (convective enthalpy, enthalpy transfer from reaction enthalpy, transfer of enthalpy with the mass leaving the particle) is calculated separately for the particle and for the gas temperature.

For the enthalpy conservation of a solid particle the following equation can be written:

$$
\begin{gathered}
\left(m_{\mathrm{CaCO}_{3}} c_{p \mathrm{CaCO}_{3}}+m_{\mathrm{CaO}} c_{p \mathrm{CaO}}\right) \dot{T}_{p}+\dot{m}_{\mathrm{CaCO}_{3}} c_{p \mathrm{CaCO}_{3}} T_{p}+\dot{m}_{\mathrm{CaO}} c_{p \mathrm{CaO}} T_{p} \\
=\frac{f \Delta H_{R} \dot{m}_{\mathrm{CaCO}_{3}}}{M_{\mathrm{CaCO}_{3}}}+\alpha A\left(T_{g}-T_{p}\right)-\dot{m}_{\mathrm{CO}_{2}} \tilde{c}_{p} T_{p},
\end{gathered}
$$

where $f$ is a factor, which represents the fraction of reaction enthalpy taken from the particle and $\tilde{c}_{p}$ is the difference of molar specific heat capacities of limestone and lime, divided by the molecular weight of carbon dioxide. In the calculations shown below the factor $f$ has been taken as 0.5 assuming that the reaction enthalpy is provided at equal parts from both particles and gaseous surrounding. However, a sensitivity study showed that at least for small particles the effect of parameter $f$ on the calcination rate is not significant, i.e. $f=0$ assuming that all

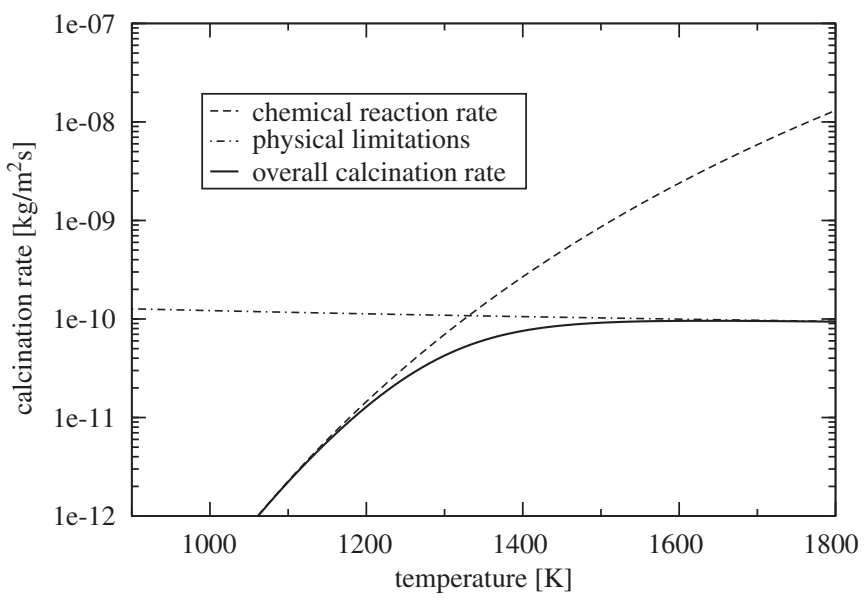

Fig. 2. Impact of the chemical reaction rate and the physical limitations on the overall reaction rate. enthalpy is taken immediately from the gas phase did not change the results.

Similar to the enthalpy balance for the solid particle, the enthalpy of the gas phase is

$$
\begin{aligned}
\sum m_{i}\left(c_{p i}+\frac{d c_{p i}}{d T} T\right) \dot{T}_{g}+\dot{m}_{\mathrm{CO}_{2}} c_{p \mathrm{CO}_{2}} T_{g} \\
=\left(\frac{-(1-f) \Delta H_{R} \dot{m}_{\mathrm{CaCO}_{3}}}{M_{\mathrm{CaCO}_{3}}}+\alpha A\left(T_{p}-T_{g}\right)\right) n_{p}+\dot{m}_{\mathrm{CO}_{2}} \tilde{c}_{p} T_{p} .
\end{aligned}
$$

From these equations the rate of change of particle and gas temperatures are calculated. The mass and enthalpy balance equations given above are applied in each cell of the computational domain during the integration of the Lagrangian particle phase for updating the gas and particle properties and are solved by time step subcycling using DVODE solver. This is done within every two gas phase time steps. Complex chemistry systems in FIRE solver are usually treated by pre-tabulation or similar methods (Ban and Duić, 2011), but in this case the calcination process, represented by one reaction (see Eq. (2)), is calculated directly. Additionally from these equations the source terms for species mass and enthalpy are collected transferring the impact of the chemical reactions from the particles to the Eulerian solver.

\subsection{Radiative heat transfer}

The radiative heat transfer and the effects of particle radiation from the limestone particles is modelled with the $\mathrm{P}-1$ radiation model (Sazhin et al., 1996; Brewster and Kunitomo, 1984):

$\nabla(\Gamma \nabla G)=\left(a+a_{p}\right) G-4 \pi\left(a \frac{\sigma T^{4}}{\pi}+E_{p}\right) \quad\left[\frac{W}{m^{3}}\right]$,

where the term on the left hand side represents the change of the incident radiation. The first term on the right hand side represents the absorption, from the continuous phase and the particles, and the second term on the right hand side represents the emission, again from the continuous phase and the particles.

For the particle emission $E_{p}$ the following correlation is used:

$E_{p}=\frac{1}{\Delta V} \sum_{n=1}^{N} \varepsilon_{p n} A_{p n} \frac{\sigma T^{4}}{\pi}\left[\frac{W}{m^{3}}\right]$

while the particle absorption coefficient is calculated as

$a_{p}=\frac{1}{\Delta V} \sum_{n=1}^{N} \varepsilon_{p n} A_{p n}\left[\frac{1}{m}\right]$.

The diffusion coefficient $\Gamma$ is calculated as

$\Gamma=\frac{1}{3\left(a+a_{p}+\sigma_{p}\right)}[m]$,

and for the particle scattering factor $\sigma_{p}$ the following correlation is used:

$\sigma_{p}=\frac{1}{\Delta V} \sum_{n=1}^{N}\left(1-f_{p n}\right)\left(1-\varepsilon_{p n}\right) A_{p n}\left[\frac{1}{m}\right]$.

The source term that is directly introduced into the enthalpy equation as a radiative heat source is calculated as follows:

$-\nabla q_{r}=-4 \pi\left(a \frac{\sigma T^{4}}{\pi}+E_{p}\right)+\left(a+a_{p}\right) G\left[\frac{W}{m^{3}}\right]$.

\section{Single particle test and results}

For the plausibility checks and the quantitative checks of balances, presented model of the calcination process was tested on a single particle in a single mesh cube. Different types of initial 
conditions were set-up (e.g., temperature, carbon dioxide content, particle diameter) to test the presented numerical model.

For calculations of a single particle, the results of which are shown in Figs. 3 and 4, initial particle diameter was set to $10 \mu \mathrm{m}$, the porosity factor, i.e. $A_{\text {por }} / A_{\text {geom }}$, was set to 5 and there was no carbon dioxide present in the single mesh cube.

Fig. 3 shows the influence of lower reaction temperatures on the calcination process, i.e. decomposition of limestone, and Fig. 4 shows the influence of higher reaction temperatures on the calcination process. From these two figures it is clear that the temperature increase results with an increase of limestone decomposition, which represents a reasonable physical trend.

Fig. 5 shows the influence of carbon dioxide content on the calcination process. As can be seen the increase of carbon dioxide content reduces the limestone decomposition. The initial particle diameter for this figure was $10 \mu \mathrm{m}$, porosity factor was set to 5 , the gas temperature was set to $1200 \mathrm{~K}$ and the carbon dioxide was the variable parameter.

Fig. 6 shows the influence of particle size on the calcination process. As can be seen bigger limestone particles need more time to decompose than the small particles. For this figure the initial gas temperature was set to $1400 \mathrm{~K}$, the porosity factor was set to 5 and initially there was no carbon dioxide.

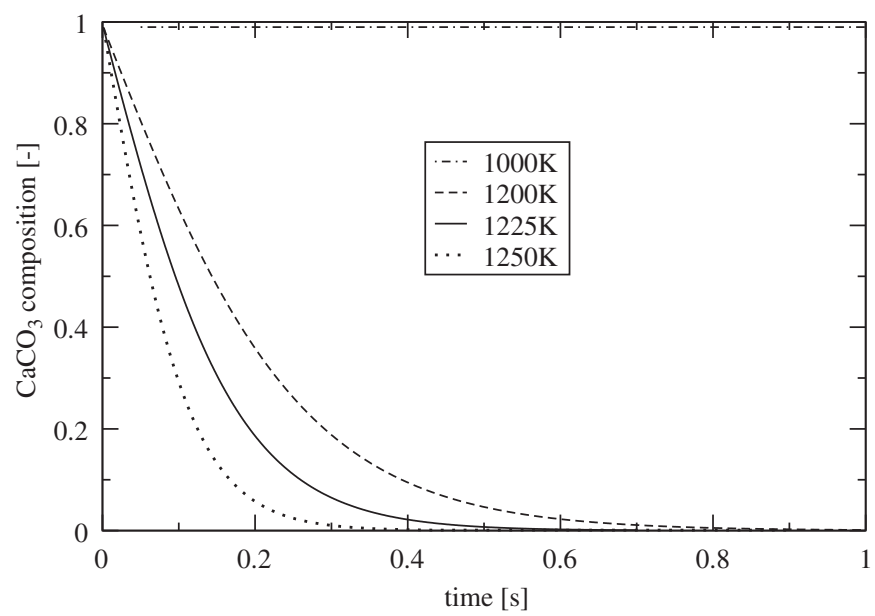

Fig. 3. Calcination process at lower reaction temperatures.

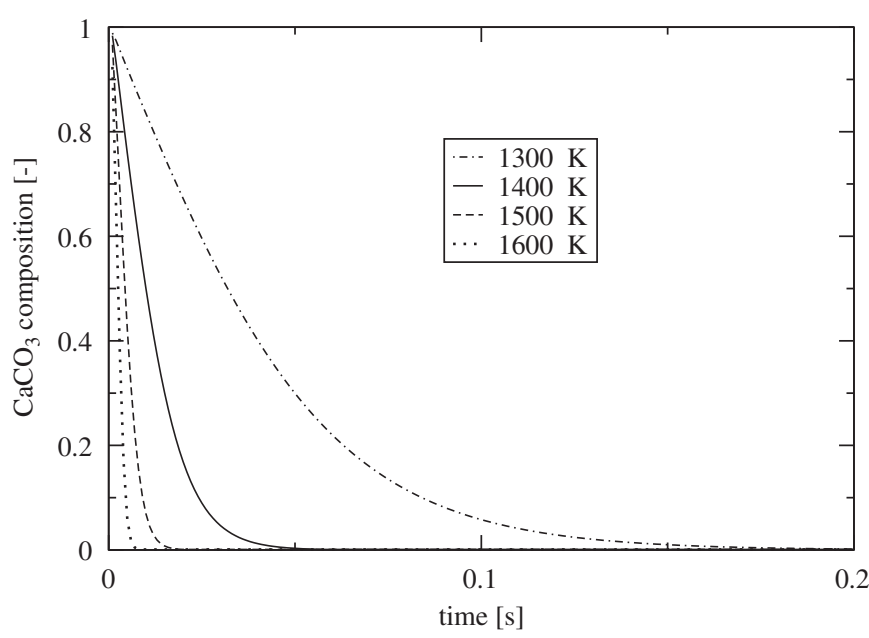

Fig. 4. Calcination process at higher reaction temperatures.

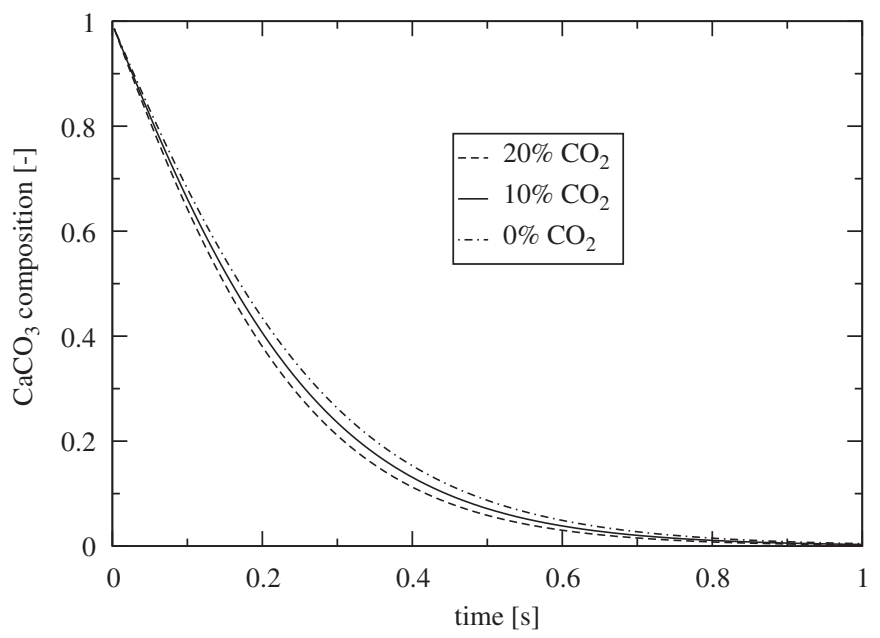

Fig. 5. Influence of $\mathrm{CO}_{2}$ content on the calcination process.

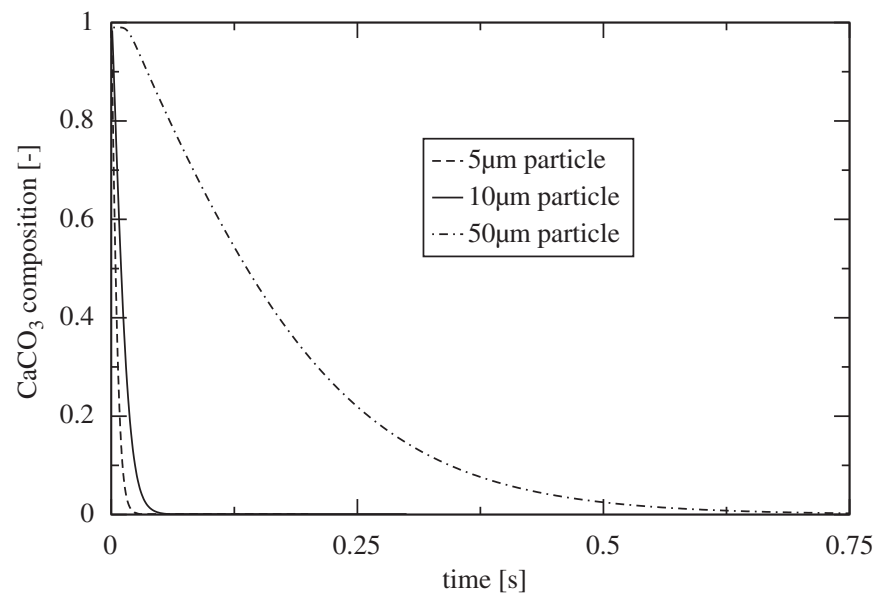

Fig. 6. Influence of particle size on the calcination process.

Results gained from the single particle tests show that the right range of particle temperatures is covered, that the conversion of limestone depends on the carbon dioxide content and that the reaction kinetics of the calcination process are able to obtain reasonable trends. Additional studies regarding the effects of pore diameter and porosity still need to be done in further work.

\section{Validation test - calcination process in a pipe reactor}

The calcination model was validated by simulating the International Flame Research Foundation (IFRF) pipe reactor IPFR (intensified plug flow reactor), for which measurements of limestone conversion exist (Mohr, 2001). Several experiments with different operating conditions have been done. This sensitivity analysis gives some more information about the influence of various parameters $\left(\mathrm{CO}_{2}\right.$ content, temperature, mass flow, etc.) on the calcination reaction rate.

\subsection{Experimental data}

The IPFR is a laboratory reactor (Fig. 7) made up of a $2 \mathrm{~m}$ long tube with a steady radial and axial temperature profile (electrically heated walls). Different gas velocities and gas compositions as well as powder mass flows can be adjusted and a sampling device to monitor the progress of reaction along the tube axis is available. This pipe reactor works up to a temperature of $1400{ }^{\circ} \mathrm{C}$. 


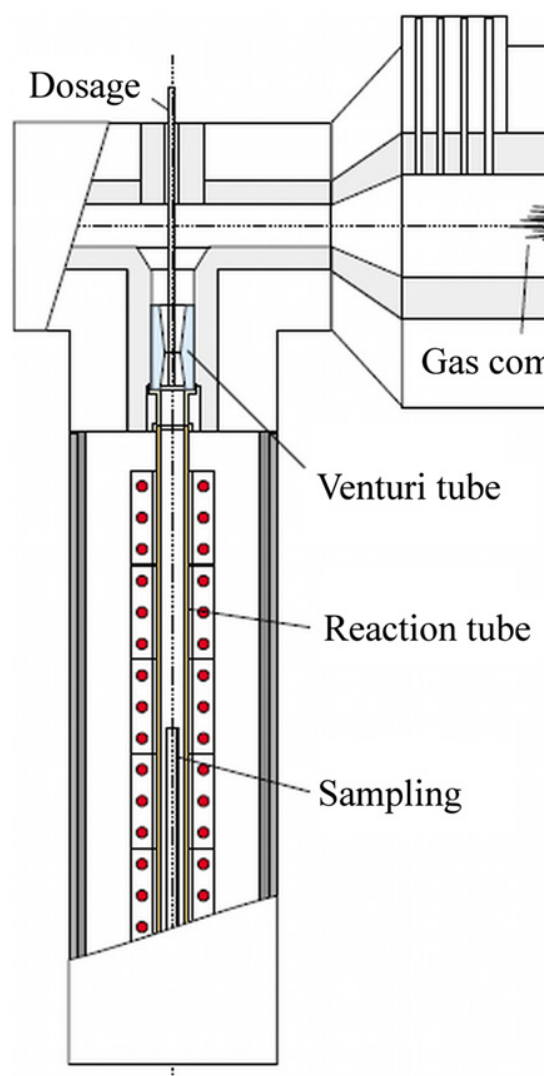

Fig. 7. Construction of IPFR pipe reactor (Mohr, 2001).

Table 1

Experimental settings (Mohr, 2001)

\begin{tabular}{|c|c|c|c|c|c|c|c|}
\hline \multirow[t]{2}{*}{ Parameter } & \multirow[t]{2}{*}{ Unit } & \multicolumn{6}{|c|}{ Calcination } \\
\hline & & $\mathrm{C} 1$ & $\mathrm{C} 2$ & $\mathrm{C} 3$ & $\mathrm{C} 4$ & C5 & C6 \\
\hline$\dot{V}_{g}$ & $\mathrm{~m}_{\mathrm{N}}^{3} / \mathrm{h}$ & 35.1 & 31.1 & 22.0 & 21.0 & 22.0 & 28.3 \\
\hline $\mathrm{O}_{2}$ & Vol\% & \multicolumn{6}{|c|}{5} \\
\hline $\mathrm{CO}_{2}$ & Vol\% & \multicolumn{4}{|c|}{14} & 19 & 8.5 \\
\hline $\mathrm{H}_{2} \mathrm{O}$ & Vol\% & \multicolumn{6}{|c|}{9.5} \\
\hline$\dot{T}_{g}$ & ${ }^{\circ} \mathrm{C}$ & 1000 & 1100 & 1200 & 1350 & 1200 & \\
\hline$\dot{m}_{\mathrm{CaCO}_{3}}$ & $\mathrm{~g} / \mathrm{h}$ & 900 & & 600 & & & \\
\hline
\end{tabular}

Reaction pipe dimensions:

Length: $l=2000 \mathrm{~mm}$

Inner diameter: $D_{1}=80 \mathrm{~mm}$

Outer diameter: $D_{2}=117 \mathrm{~mm}$

The experimental data forms the basis for the evaluation of the calcination model and its simulation behaviour. The experiments were performed according to Table 1 .

Finally following the procedure of Mohr (2001) a Rosin-Rammler distribution is assumed for limestone particle size distribution, with the mean particle diameter $d^{\prime}=10.68 \mu \mathrm{m}$, the smallest diameter $0.1 \mu \mathrm{m}$, the largest diameter $62.93 \mu \mathrm{m}$ and the spread parameter $n=0.653$.

Rosin-Rammler distribution function is

$R(d)=\exp \left[-\left(\frac{d}{d^{\prime}}\right)^{n}\right]$

\subsection{Numerical simulation}

In the simulation 10,800 cells were employed to discretize the computational domain, extending from 0 to $2000 \mathrm{~mm}$ in axial direction and from 0 to $80 \mathrm{~mm}$ in radial direction, representing the reaction tube (Fig. 7). For the validation test six different setups were calculated according to Table 1 . The differencing scheme used for momentum and continuity balances was Central Differencing, and for turbulence, energy balances and scalar transport equations an Upwind scheme was applied. Turbulence was modelled by the standard $k-\varepsilon$ model.

\subsection{Results and discussion}

The predicted conversion of limestone to lime, for different setups, was compared with the calculations from Mohr's doctoral dissertation and the reported experimental data (Mohr, 2001). Fig. 8 shows the influence of pore diameter on the results for the $\mathrm{C} 3$ experiment. It is clear that with higher values of pore diameter conversion of limestone to lime is higher. Fig. 9 shows the influence of void fraction on the results for the $\mathrm{C} 3$ experiment. As can be seen higher values of void fraction increase the conversion of limestone to lime. Fig. 10 shows the influence of tortuosity on the results for the C3 experiment. It is clear that higher values of tortuosity give slower conversion effect. The rest of the figures show the

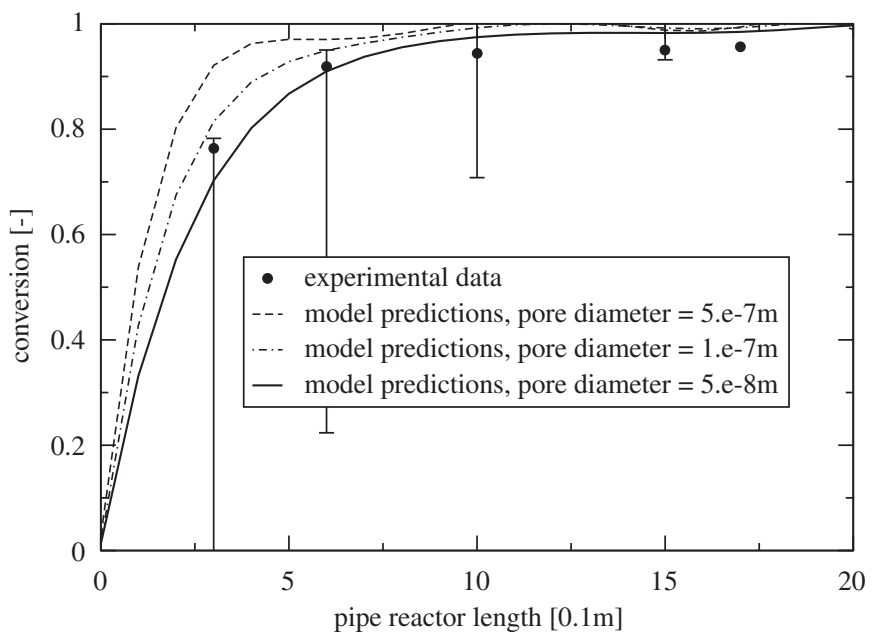

Fig. 8. Influence of pore diameter on the results for the $C 3$ experiment.

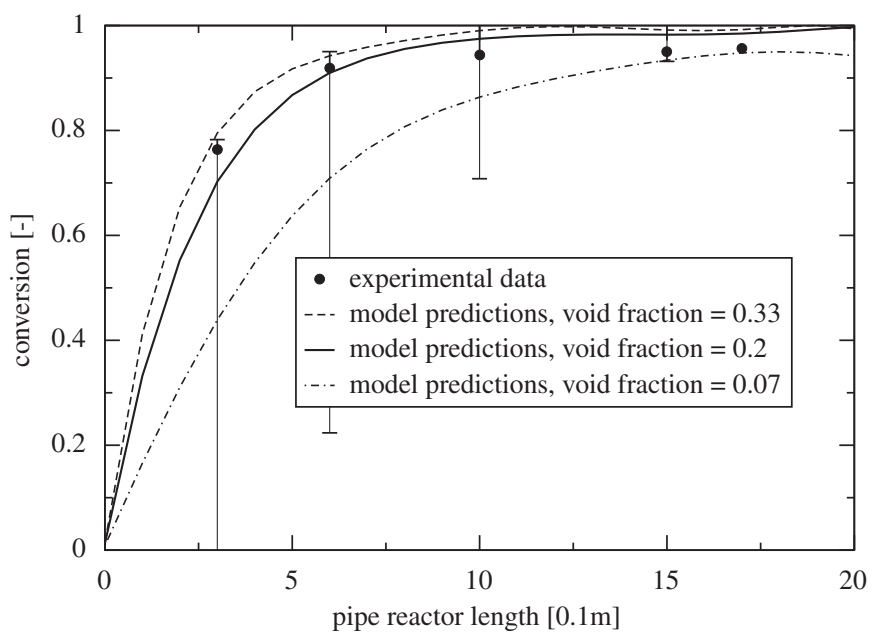

Fig. 9. Influence of void fraction on the results for the $\mathrm{C} 3$ experiment. 


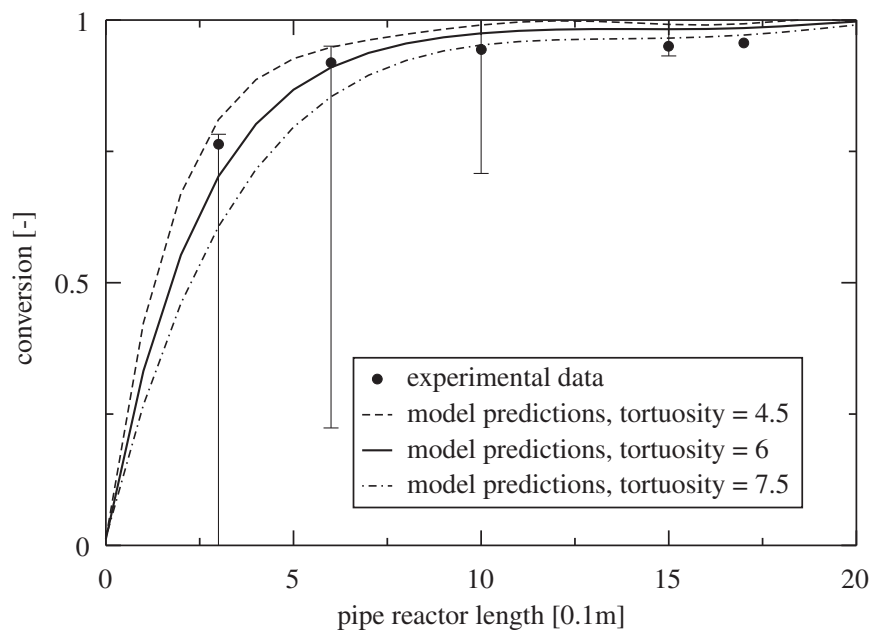

Fig. 10. Influence of tortuosity on the results for the $C 3$ experiment.

comparison of the predicted limestone conversion, using the combined reaction rate with pore diffusion, with Mohr's calculation and the experimental measurements along the pipe reactor for all setups presented in Table 1. All of the calculations have been done with the same set of model parameters using the value of 6 for tortuosity (Wang et al., 2005), 0.2 for void fraction and $5 \mathrm{e}-8 \mathrm{~m}$ for pore diameter. In the literature (Bluhm-Drenhaus et al., 2010; Stanmore and Gilot, 2005) higher values for the void fraction in the range of $0.36-0.68$ are given. The lower value of 0.2 assumed in this work can be justified by sintering processes as described by Hillers (2008), which can reduce again the porosity considerably to values down to 0.05 depending on temperature and particle residence time.

As can be noted the experimental measurements and the numerical results obtained by the calcination model are in good agreement. From the shown results it is clear that the presented model follows the influence of temperature as can be concluded from comparison of $\mathrm{C} 1$ and $\mathrm{C} 2$ as well as C3 and C4, which differ by temperature only. The effect of reduced conversion with increasing carbon dioxide content varied in C3 and C5, which is not that clearly visible, but the calculated curves are anyway close to the experimental mean values and always within the experimental uncertainty range. Further comparing C5 and C6 the same trend of reduced conversion with increasing gas mass flow can be detected in both experiments as well as in the calculations. This occurs despite the reduction of the carbon dioxide content at the same time, which should enhance conversion. Thus the effect can be understood by the reduced particle residence time connected with enhanced gas mass flow.

Fig. 11 shows the influence of mesh size on the results for the C3 experiment. Comparison of the coarsest grid (dotted line) and the coarse grid (dash dot line) shows significant differences in the results, while the difference between intermediate (continuous line) and fine grid (dashed line) is already considerably smaller. The conversion rate of these two grids (continuous and dashed line) is almost identical. Thus with respect to the experimental uncertainty the grid with 10,800 cells has been regarded as sufficient.

In Figs. 12-17 also the calculations from the Ph.D. thesis of Mohr (2001) are shown. Despite the fact that the model presented is simpler than the Mohr model, e.g. regarding details of evolution of the porous structure and detailed description of sintering processes, the overall agreement with the experimental data could be improved. This might be due to the additional uncertainties in Mohr's model introduced by unknown model parameters of the detailed sub-models and complex interactions

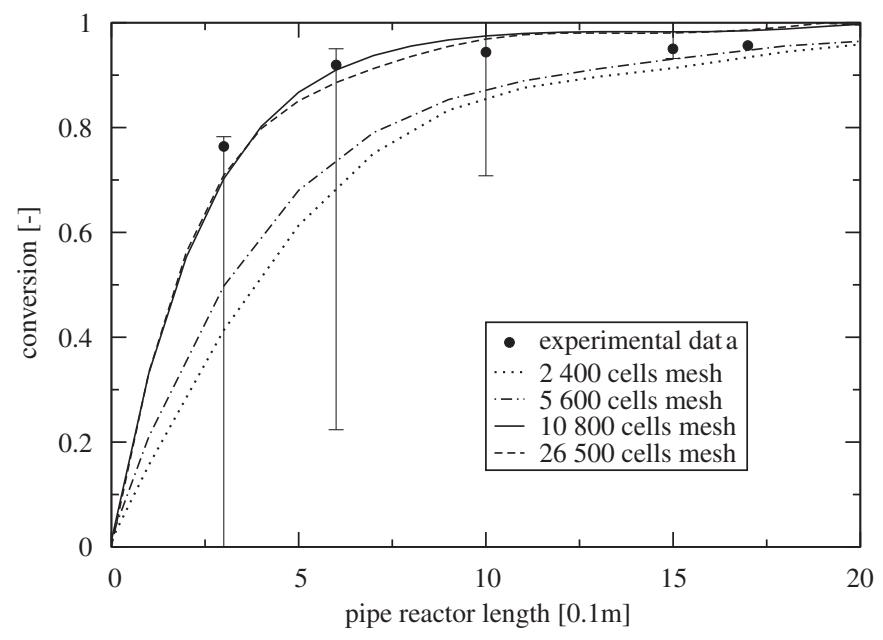

Fig. 11. Influence of mesh size on the results for the $C 3$ experiment.

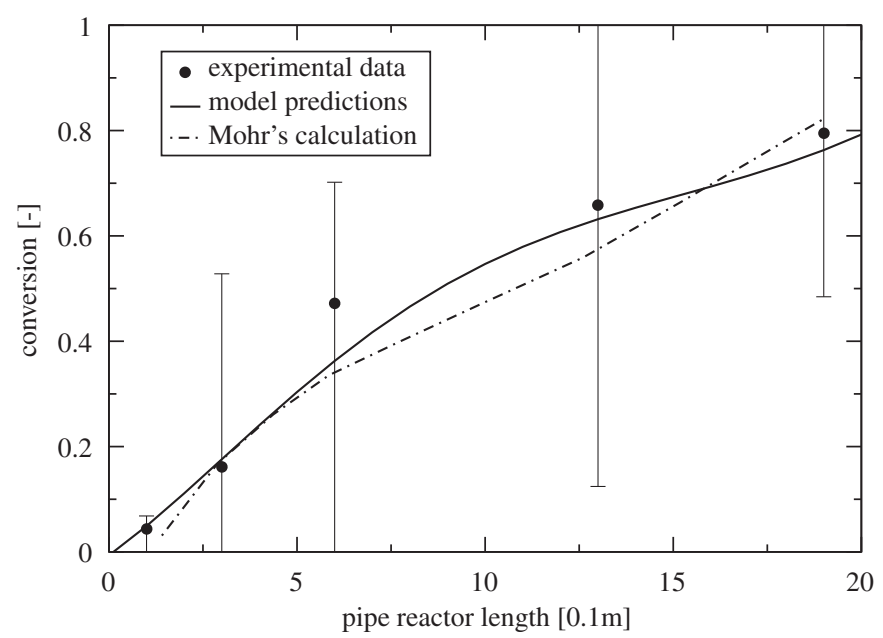

Fig. 12. Comparison of $\mathrm{C} 1$ set-up.

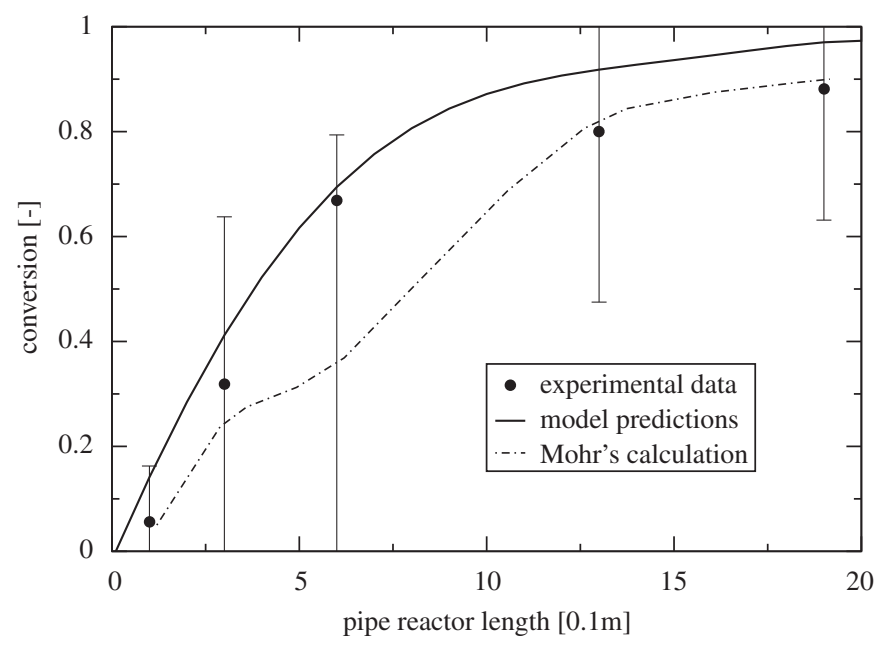

Fig. 13. Comparison of $\mathrm{C} 2$ set-up.

between them, which would need an even broader experimental data base for adjustment. In contrast to this the simpler model can be more easily controlled and matched and thus is judged to be sufficiently accurate for CFD simulations of the overall calcination process. Nevertheless the refined models from the literature are the valuable basis for further model extensions. 


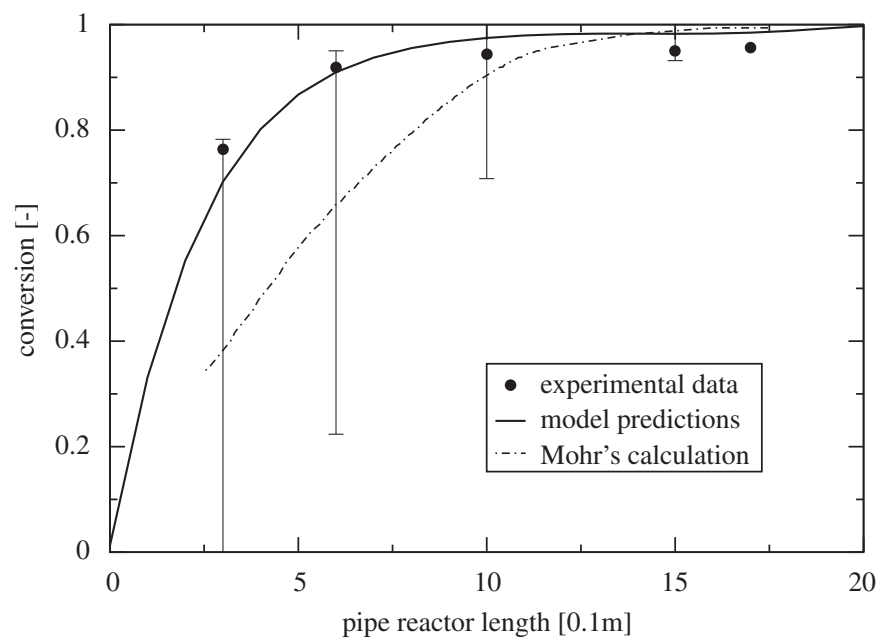

Fig. 14. Comparison of $\mathrm{C} 3$ set-up.

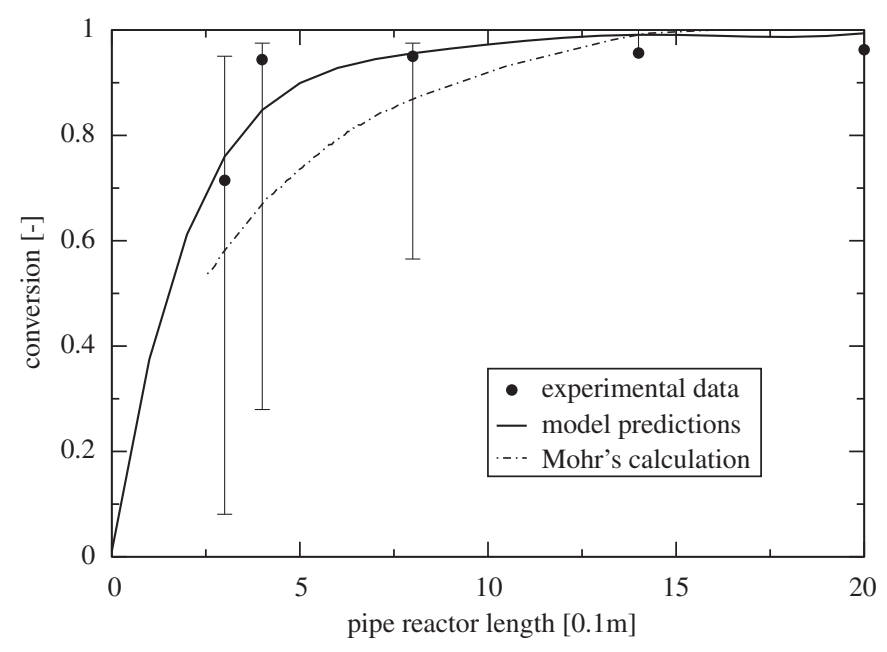

Fig. 15. Comparison of $\mathrm{C} 4$ set-up.

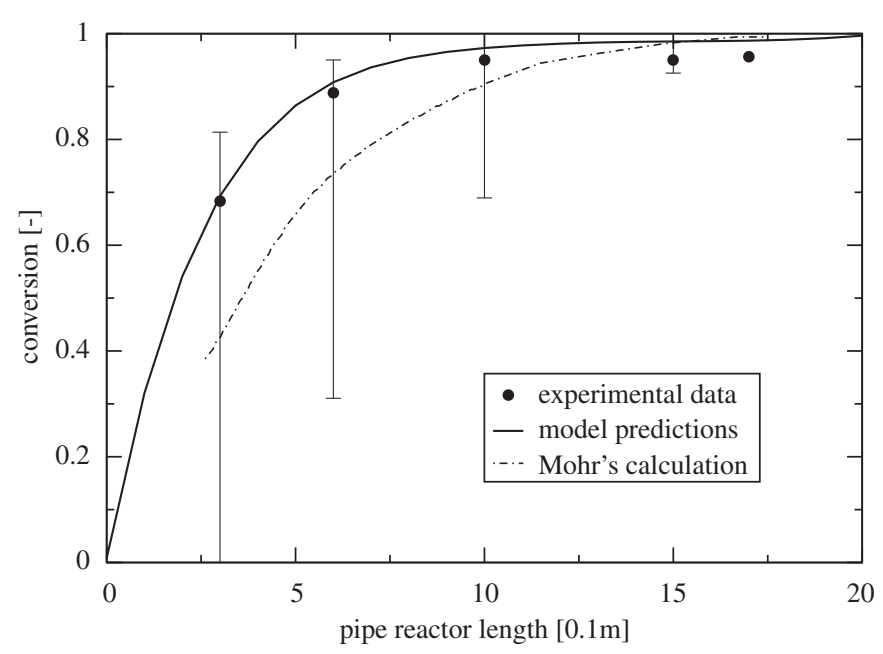

Fig. 16. Comparison of C5 set-up.

\section{Conclusion}

The formation of carbon dioxide in cement production systems has created increasing environmental concerns because of the reductions in carbon dioxide emissions. Thus, investigations of

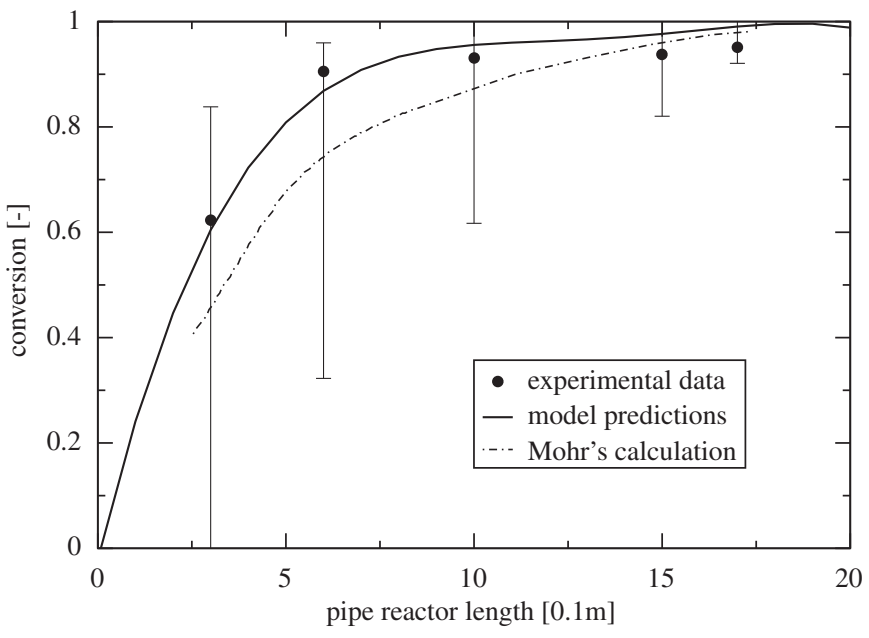

Fig. 17. Comparison of C6 set-up.

various thermo-chemical reaction techniques, which can be used to reduce carbon dioxide emission, have become a major area of the current research. Computer modelling of the calcination process provides a valuable tool that can be used for the investigation and better understanding of particle kinetics and pollutant emissions from cement combustion systems.

The numerical model of the calcination process was implemented into a commercial CFD code FIRE, taking into account the effects of temperature, decomposition pressure, diffusion and pore efficiency. The model is detailled enough to contain the relevant physical and chemical processes, yet simple enough to run on the realistic industrial meshes needed for detailed CFD simulations of calcination devices. From the results shown it can be concluded that the presented model of the calcination process is in a good agreement with the reported experimental measurements. Thus, it can be used for the investigation and optimisation of calcination devices for cement production. This will be done in future work.

\section{Nomenclature}

a absorption coefficient, $\mathrm{m}^{-1}$

$a_{p} \quad$ particle absorption coefficient, $\mathrm{m}^{-1}$

A sphere surface, $\mathrm{m}^{2}$

$A_{\text {geom }}$ sphere surface, $\mathrm{m}^{2}$

$A_{p n} \quad$ projected area of an $n$-particle, $\mathrm{m}^{2}$

$A_{\text {por }} \quad$ overall reaction surface, $\mathrm{m}^{2}$

$\tilde{c}_{p} \quad$ specific heat capacity, $\mathrm{J} \mathrm{kg}^{-1} \mathrm{~K}^{-1}$

$c_{p \mathrm{CaCO}_{3}}$ specific heat capacity of limestone, $\mathrm{J} \mathrm{kg}^{-1} \mathrm{~K}^{-1}$

$c_{p \mathrm{CaO}} \quad$ specific heat capacity of lime, $\mathrm{J} \mathrm{kg}^{-1} \mathrm{~K}^{-1}$

$c_{p i} \quad$ specific heat capacity of gas component, $\mathrm{J} \mathrm{kg}^{-1} \mathrm{~K}^{-1}$

$d \quad$ particle diameter, $m$

$d^{\prime} \quad$ mean particle diameter, $\mathrm{m}$

$d_{\text {part }} \quad$ particle diameter, $m$

$d_{\text {pore }} \quad$ pore diameter, $\mathrm{m}$

$D$ diffusion coefficient, $\mathrm{m}^{2} \mathrm{~s}^{-1}$

$D_{\text {bin }} \quad$ binary diffusion coefficient, $\mathrm{m}^{2} \mathrm{~s}^{-1}$

$D_{k n u} \quad$ Knudsen diffusion coefficient, $\mathrm{m}^{2} \mathrm{~s}^{-1}$

$E_{p} \quad$ particle emission, $\mathrm{W} \mathrm{m}^{-3}$

$f \quad$ reaction enthalpy factor, dimensionless

$f_{p n} \quad$ scattering factor of $n$-th particle, dimensionless

$G \quad$ incident radiation, $\mathrm{W} \mathrm{m}^{-2}$

$\Delta H_{R} \quad$ reaction enthalpy, $\mathrm{J} \mathrm{mol}^{-1}$

$k \quad$ overall reaction rate, $\mathrm{kg} \mathrm{m}^{-2} \mathrm{~s}^{-1}$

$\widehat{k} \quad$ overall reaction rate, $\mathrm{kg} \mathrm{s}^{-1}$ 
$k_{c h} \quad$ chemical reaction rate, $\mathrm{mol} \mathrm{m}^{-2} \mathrm{~s}^{-1}$

$\tilde{k}_{c h} \quad$ chemical reaction rate, $\mathrm{kg} \mathrm{m}^{-2} \mathrm{~s}^{-1}$

$\overline{\bar{k}}_{c h} \quad$ chemical reaction rate, $\mathrm{s}^{-1}$

$k_{D} \quad$ reaction rate, $\mathrm{mol} \mathrm{m} \mathrm{m}^{-2} \mathrm{~s}^{-1} \mathrm{~Pa}^{-1}$

$k_{p h} \quad$ physical reaction rate, $\mathrm{kg} \mathrm{m}^{-2} \mathrm{~s}^{-1}$

$m_{\mathrm{CaCO}_{3}}$ limestone mass, $\mathrm{kg}$

$m_{\mathrm{CaO}} \quad$ lime mass, $\mathrm{kg}$

$\dot{m}_{\mathrm{CO}_{2}} \quad$ mass transfer of $\mathrm{CO}_{2}, \mathrm{~kg} \mathrm{~s}^{-1}$

$\dot{m}_{\mathrm{CaCO}_{3}}$ mass transfer of limestone, $\mathrm{kg} \mathrm{s}^{-1}$

$\dot{m}_{\mathrm{CaO}} \quad$ mass transfer of lime, $\mathrm{kg} \mathrm{s}^{-1}$

$m_{i} \quad$ gas component mass, $\mathrm{kg}$

$M_{A B} \quad$ average molecular weight, $\mathrm{g} \mathrm{mol}^{-1}$

$M_{\mathrm{CO}_{2}} \quad \mathrm{CO}_{2}$ molecular weight, $\mathrm{g} \mathrm{mol}^{-1}$

$\mathrm{M}_{\mathrm{CaCO}_{3}} \quad$ limestone molecular weight, $\mathrm{g} \mathrm{mol}^{-1}$

$M_{\mathrm{CaO}} \quad$ lime molecular weight, $\mathrm{g} \mathrm{mol}^{-1}$

$n \quad$ particle spread parameter, dimensionless

$n_{p} \quad$ number of particles per parcel, dimensionless

$p \quad$ total pressure, $\mathrm{Pa}$

$p_{\mathrm{CO}_{2}} \quad \mathrm{CO}_{2}$ partial pressure, $\mathrm{Pa}$

$p_{e q} \quad$ equilibrium $\mathrm{CO}_{2}$ partial pressure, $\mathrm{Pa}$

$p_{\text {ref }} \quad$ referent pressure, $\mathrm{Pa}$

$q_{r} \quad$ radiation flux, $\mathrm{W} \mathrm{m}^{-2}$

$R \quad$ Rosin-Rammler distribution function, dimensionless

$R_{\mathrm{CO}_{2}} \quad \mathrm{CO}_{2}$ gas constant, $\mathrm{J} \mathrm{kg}^{-1} \mathrm{~K}^{-1}$

$S_{\varphi} \quad$ source term of the dependent variable $\varphi$

Sh Sherwood number, dimensionless

$T$ temperature, $\mathrm{K}$

$T_{g} \quad$ gas temperature, $\mathrm{K}$

$T_{p} \quad$ particle temperature, $\mathrm{K}$

$u_{j} \quad$ Cartesian velocity, $\mathrm{m} \mathrm{s}^{-1}$

\section{Greek letters}

$\alpha \quad$ convective heat transfer coefficient, $\mathrm{W} \mathrm{m}^{-2} \mathrm{~K}^{-1}$

$\Gamma \quad$ diffusion coefficient, $\mathrm{m}$

$\Gamma_{\varphi} \quad$ diffusion coefficient of the dependent variable $\varphi$

$\varepsilon \quad$ correction factor, dimensionless

$\varepsilon_{p} \quad$ void fraction (porosity), dimensionless

$\varepsilon_{p n} \quad$ emissivity of $\mathrm{n}$-th particle, dimensionless

$\varphi \quad$ dependent variable

$\eta \quad$ pore efficiency factor, dimensionless

$\rho$ density, $\mathrm{kg} \mathrm{m}^{-3}$

$\sigma \quad$ Stefan-Boltzmann's constant, $\mathrm{W} \mathrm{m} \mathrm{m}^{-2} \mathrm{~K}^{-4}$

$\sigma_{A B} \quad$ characteristic length, $10^{-8} \mathrm{~m}$

$\sigma_{p} \quad$ particle scattering factor, $\mathrm{m}^{-1}$

$\tau_{p} \quad$ tortuosity, dimensionless

$\omega_{d} \quad$ diffusion collision integral, dimensionless

\section{References}

Baburić, M., Raulot, A., Duić, N., 2004. Implementation of discrete transfer radiation method into SWIFT computational fluid dynamics code. Therm. Sci. 8, 293-301.

Baburić, M., Duić, N., Raulot, A., Coelho, P.J., 2005. Application of the conservative discrete transfer radiation method to a furnace with complex geometry. Numer. Heat Transfer Part A Appl. 48, 297-313.

Ban, M., Duić, N., 2011. Adaptation of n-heptane autoignition tabulation for complex chemistry mechanisms. Therm. Sci. 15, 135-144.

Bes, A., 2006. Dynamic Process Simulation of Limestone Calcination in Normal Shaft Kilns. Ph.D. Thesis. Otto-von-Guericke-University, Magdeburg.
Bluhm-Drenhaus, T., Simsek, E., Wirtz, S., Scherer, V., 2010. A coupled fluid dynamic-discrete element simulation of heat and mass transfer in a lime shaft kiln. Chem. Eng. Sci. 65, 2821-2834.

Borgwart, R.H., 1985. Calcination kinetics and surface area of dispersed limestone particles. AIChE J. 31, 103-111.

Brewster, M.Q., Kunitomo, T., 1984. The optical constants of coal, char and limestone. ASME J. Heat Transfer 106, 678-683.

Campbell, F.R., Hills, A.W.D., Paulin, A., 1970. Transport properties of porous lime and their influence on the decomposition of porous compacts of calcium carbonate. Chem. Eng. Sci. 25 (1970), 929-942.

Darroudi, T., Searcy, A.W., 1981. Effect of $\mathrm{CO}_{2}$ pressure on the rate of decomposition of calcite. J. Phys. Chem. 85, 3971-3974.

Dennis, J.S., Hayhurst, A.N., 1987. The effect of $\mathrm{CO}_{2}$ on the kinetics and extent of calcinations of limestone and dolomite particles in fluidised beds. Chem. Eng. Sci. 42, 2361-2372.

Fidaros, D.K., Baxevanou, C.A., Dritselis, C.D., Vlachos, N.S., 2007. Numerical modelling of flow and transport processes in a calciner for cement production. Powder Technol. 171, 81-95.

Froment, G., Bischoff, K., 1990. Chemical Reactor Analysis and Design, second ed. J. Wiley and Sons, New York (pp. 160).

Garcia-Labiano, F., Abad, A., de Diego, L.F., Gayan, P., Adanez, J., 2002. Calcination of calcium-based sorbents at pressure in a broad range of $\mathrm{CO}_{2}$ concentrations. Chem. Eng. Sci. 57, 2381-2393.

Hillers, M., 2008. Modellierung der Turbulenzmodulation einer hochbeladenen reaktiven Zweiphasenströmung am Beispiel des Zementherstellungsprozesse. Ph.D. Thesis. University Duisburg-Essen.

Hills, A.W.D., 1968. The mechanism of the thermal decomposition of calcium carbonate. Chem. Eng. Sci. 23, 297-320.

Hu, N., Scaroni, A.W., 1996. Calcination of pulverised limestone particles under furnace injection conditions. Fuel 75, 177-186.

Hu, Z., Lu, J., Huang, L., Wang, S., 2006. Numerical simulation study on gas-solid two-phase flow in pre-calciner. Commun. Nonlinear Sci. Numer. Simulation $11,440-451$.

Huang, L., Lu, J., Xia, F., Li, W., Ren, H., 2006. 3-D mathematical modeling of an inline swirl-spray precalciner. Chem. Eng. Process. 45, 204-213.

Huanpeng, L., Wentie, L., Jianxiang, Z., Ding, J., Xiujian, Z., Huilin, L., 2004. Numerical study of gas-solid flow in a precalciner using kinetic theory of granular flow. Chem. Eng. J. 102, 151-160.

Iliuta, I., Dam-Johansen, K., Jensen, A., Jensen, L.S., 2002a. Modeling of in-line low- $\mathrm{NO}_{x}$ calciners - a parametric study. Chem. Eng. Sci. 57, 789-803.

Iliuta, I., Dam-Johansen, K., Jensen, L.S., 2002b. Mathematical modeling of in-line low- $\mathrm{NO}_{x}$ calciner. Chem. Eng. Sci. 57, 805-820.

Ingraham, T.R., Marier, P., 1963. Kinetic studies on the thermal decomposition of calcium carbonate. Can. J. Chem. Eng. 41, 170-173.

Kern, C., Jess, A., 2006. Verkokung and Koksabbrand in heterogenen Katalysatoren. Chem. Ing. Tech. 8, 78 .

Khinast, J., Krammer, G.F., Brunner, Ch., Staudinger, G., 1996. Decomposition of limestone: the influence of $\mathrm{CO}_{2}$ and particle size on the reaction rate. Chem. Eng. Sci. 51, 623-634.

Levenspiel, O., 1972. Chemical Reaction Engineering, second ed. J. Wiley and Sons, New York (pp. 482).

Mohr, M., 2001. Numerische Simulation der simultanen Reaktion von Kalkstein und Kohle bei der Zementherstellung. Ph.D. Thesis. University of Ruhr, Bochum.

Reid, R.C., Prausnitz, J.M., Polling, B.E., 1988. The Properties of Gases and Liquids, fourth ed. McGraw-Hill Book Company, New York (pp. 582).

Sazhin, S.S., Sazhina, E.M., Faltsi-Saravelou, O., Wild, P., 1996. The P-1 model for thermal radiation transfer: advantages and limitations. Fuel 75, 289-294.

Schneider, M., 2003. Experimentelle und mathematische Modellierung der Festbettvergasung am Beispiel der Gleichstromvergasung von Holzhackschnitzeln. Ph.D. Thesis. TU, Dresden.

Silcox, G.D., Kramlich, J.C., Pershing, D.W., 1989. A mathematical model for the flash calcination of dispersed $\mathrm{CaCO}_{3}$ and $\mathrm{Ca}(\mathrm{OH})_{2}$ particles. Ind. Eng. Chem. Res. 28, 155-160.

Stanmore, B.R., Gilot, P., 2005. Review-calcination and carbonation of limestone during thermal cycling for $\mathrm{CO}_{2}$ sequestration. Fuel Process. Technol. 86, 1707-1743.

Vujanović, M., Duić, N., Galović, A., 2007. Three-dimensional numerical simulation of the nitrogen oxides formation in an oil-fired furnace. Strojarstvo 49, $165-171$.

Vujanović, M., Duić, N., Tatschl, R., 2009. Validation of reduced mechanisms for nitrogen chemistry in numerical simulation of a turbulent non-premixed flame. React. Kinet. Catal. Lett. 96, 125-138.

Vujanović, M., 2010. Numerical Modeling of Multiphase Flow in Combustion of Liquid Fuel. Ph.D. Thesis. University of Zagreb.

Wang, R., Pavlin, T., Rosen, M.S., Mair, R.W., Cory, D.G., Walsworth, R.L., 2005. Xenon NMR measurements of permeability and tortuosity in reservoir rocks. Magn. Reson. Imaging 23, 329-331. 